valuable to naturalists has been replaced by a concept of their role as living museums, and outdoor laboratories, to be fully and systematically studied by scientists, with the view of understanding their ecosystems, biological productivity, population dynamics, successional and land-use history, and so forth. The assumption that any necessary management of reserves can be satisfactorily achieved empirically has been replaced by a comprehensive, two-tier programme of concerted basic and applied ecological researches, designed to elucidate the full range of fundamental principles involved, and to develop the necessary series of techniques and prescriptions for their application. It is also now recognized that not only natural and semi-natural habitats displaying various stages of ecological succession are equally deserving of care and protection in the interests of science, but also modified or induced ecosystems and sites, already used for, or well suited to, ecological investigations. Local distributions are now being systematically and comprehensively mapped, as well as changes and trends in populations. The lack of interest of universities in ecology and conservation has been replaced by a rapid growth of specialized postgraduate courses, and there has been a major increase in the number of students taking doctorates in ecological subjects and a general growth in university field studies, partly at the centres of the Field Studies Council.

The essential role of basic and applied ecology in the training and practice of the land professions, such as forestry, agriculture, fisheries, estate management, land- scape architecture and town and country planning, is now bocoming recognized, as well as the need for increased understanding of the character, scale and causes of human impacts on Nature, both through studies and analysis and through improved communications between the different interests concerned. Applied ecology is now recognized as being the guidance of the proper control of the use of potentially polluting substances, such as toxic chemicals, as well as the promotion, through concerted action and the wise multi-purpose use of land and natural resources, of the general adoption and observance of modern conservation practices.

Mr. Nicholson's thesis is that scientific ecology has now reached the point of transforming the concepts of management of natural areas, and is beginning to make a serious impact on the use and management of land, education, and interests concerned with the use of renewable natural resources. He illustrates this by summarizing the British contribution on an international plane and by reviewing the position in the various counties of England and Northern Ireland. The distinction between conservation movements in Britain and other countries is based far more on the naturalist tradition, on which professional work in biology has lately been superimposed. The centre of gravity of the whole movement is shifting steadily from the saving of species, and even of habitats, to a broader view of conservation as involving the scientific care and good management of man's entire natural environment.

\title{
ORIGIN OF ATYPICAL METEORITES FROM THE ARIZONA METEORITE CRATER
}

\author{
By Prof MICHAEL E. LIPSCHUTZ \\ Department of Chemistry, Purdue University, Lafayette, Indiana
}

\begin{abstract}
$\mathrm{T}$ HE well-known Arizona Meteorite Crater is an impact feature having a diameter of nearly $1 \mathrm{~km}$. Estimates of the mass of the meteoroid which produced it have ranged from 30,000 (ref. 1) to $2 \cdot 6$ million $^{2}$ metric tons. The (spherical) diameters corresponding to these estimates are $20 \mathrm{~m}$ and $86 \mathrm{~m}$. The main mass of this meteoroid has never been located. Inasmuch as most of the meteoroid probably vaporized or mixed with the surrounding rock during the explosion, it seems rather unlikely that much of the mass will ever be found. However, a fraction did survive the explosion in the form of many thousands of fragments ranging up to $640 \mathrm{~kg}$ in weight. The overwhelming preponderance of these have been 'normal' coarse octahedrites with kamacite band-widths ranging up to 4-5 mm. Less than 12 of the recovered fragments had structures corresponding to those of medium octahedrites. These atypical meteorites have been called Canyon Diablo No. 2, Canyon Diablo No. 3 and Monument Rock $^{3}$. There is no doubt that these three types differ significantly both from the normal Canyon Diablo meteorites and among themselves ${ }^{4}$ in structure and chemical composition.
\end{abstract}

Four explanations have been offered which can account for the atypical samples. The first of these is that the meteoroid was not a solid mass on impact with the Earth but consisted of a swarm of much smaller objects ${ }^{5}$. The possibility of such a swarm seems rather remote ${ }^{3}$, and will not be considered further here. A second possíbility is that the meteoroid consisted of a main mass of coarse octahedrite structure and several satellites with the medium octahedrite structures ${ }^{3}$. A third explanation is that there were four distinct falls: a large crater-forming coarse octahedrite mass, followed by three separate medium octahedrite falls ${ }^{3}$. The fourth possibility is that all were part of the same mass which had varying physical structures and minor element contents ${ }^{6,7}$.

Until recently, no definitive results had been obtained as to which of these explanations was correct. On the basis of cosmogenic rare-gas measurements ${ }^{6}$, Heymann was able to show that Canyon Diablo No. 2 was probably buried in the main mass of the meteoroid and exposed to cosmic-ray bombardment for $540 \pm 100$ million years at a pre-atmospheric depth of $50 \mathrm{~cm}$. The remote possibility, however, existed that it was a distinet fall with a cosmicray exposure age of $64 \pm 12$ million years. The results of the rare-gas measurements on Canyon Diablo No. 3 were rather less conclusive. Either this meteoroid was part of the main mass and had an exposure age of about 1,000 million years or it was originally in a $10^{5} \mathrm{~kg}$ object having an exposure age of $540 \pm 100$ million years (either a protuberance on the main mass or as a separate $10^{5} \mathrm{~kg}$ mass). Similar a!ternatives ${ }^{7}$ were proposed in order to explain the observed rare-gas contents of sample 24 , a normal Canyon Diablo. However, a subsequent ${ }^{40} \mathrm{~K} /{ }^{41} \mathrm{~K}$ measurement by Voshage ${ }^{8}$ of sample 24 yielded a value in substantial agreement with the exposure age of 540 million years. This result casts considerable doubt on the validity of the exposure age of 1,000 million years for Canyon Diablo No. 3. Most of the known measured medium octahedrites have exposure ages in the 500-600 million year range ${ }^{8,8}$ and it is therefore not possible from Heymann's measurements to decide whether Canyon Diablo No. 3 was located in a $10^{5} \mathrm{~kg}$ projection from the infinite mass $\left(\gg 2 \times 10^{5} \mathrm{~kg}\right.$ ) meteoroid or was a separate fall. $A$ number of recent investigation $\mathbf{s}^{3,7,10}$ have established the fact that all known normal Canyon Diablo meteorites found on the Crater rim have been shocked to at least $130 \mathrm{~kb}$. Since all three atypical types were recovered 


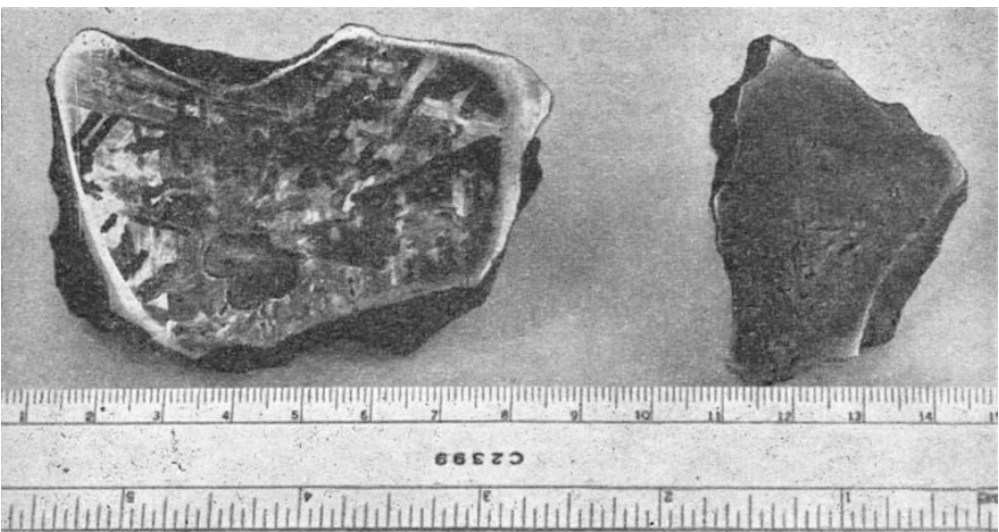

Hig. 1. Comparison between the apparently normal, undeformed Widmannstätten pattern of the moderately shocked Canyon Diablo No. 3 sample (left) with the faint on the polished surface of the Canyon Diablo No. 3 are $\varepsilon$ iron

graphic character of the cohenite, which has been shocked to about 1,000 $\mathrm{kb}^{12}$.

Canyon Diablo No. 3. This meteorite falls into the moderately shocked category $(130-750 \mathrm{~kb})$ of Heymann et al. ${ }^{\text {? }}$. Tho Widmanstätten pattern is quite distinct and undeformed although the macrostructure shows areas of $\varepsilon$ iron (Fig. 1). Pressure gradients are very common. Some kamacite areas show normal Noumann bands, while othors show regions of finely recrystallized kamacite around inclusions, or aroas of complotely recrystallized kamacite. Some of the patches of $\varepsilon$ iron are normal, while others are in the process of conversion to polycrystalline kamacite (Fig. 4). The rhabdite and schreibersite $\left(\mathrm{Fe}_{3} \mathrm{P}\right)$ grains are apparently thermally unaltered. Some cohenite grains show borders of martensite, but most exhibit no carbon diffusion

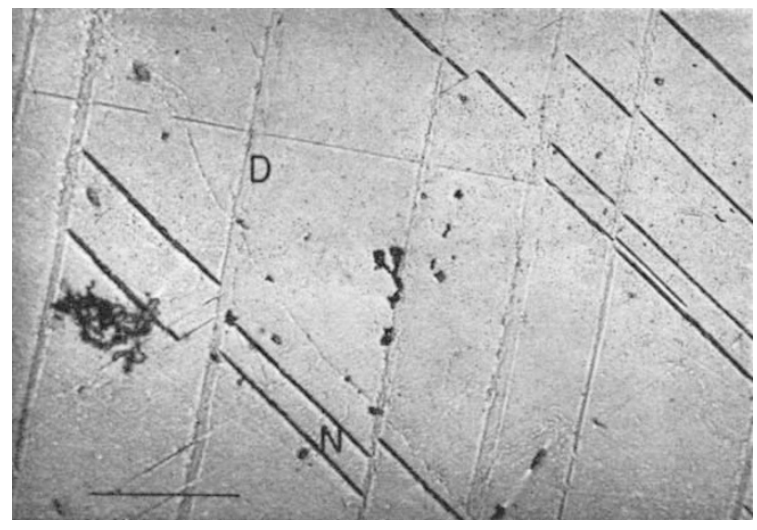

Fig. 2. Microstructure of the lightly shocked Monument Rock meteorite showing deformation bands $(D)$ and Neumann bands $(N)$. 'The bar in these figures is $0.1 \mathrm{~mm}$

from the north-east rim ${ }^{11}$ it seemed reasonable to examine them for shock effects in an attempt to resolve the question of their origin.

With the help of Prof. C. B. Moore, curator of the Nininger Meteorite Collection, I obtained samples of Canyon Diablo No. 2 (371.3), Canyon Diablo No. 3 (586.1), and Monument Rock (587.1x). The first two of these are shown in Fig. 1. Monument Rock is illustrated in Plate 22, Fig. $2 E$ of ref. 3 . These samples were polished and examined by standard metallographic techniques. The detailed interpretation of shock-induced metallographic changes in meteoritic iron have been described previously ${ }^{7,10}$ and need not be repeated here.

Monument Rock. This meteorite falls into the lightly shocked category $\left(<130 \mathrm{~kb}\right.$ ) of Heymann et al. ${ }^{7}$. The large number of Neumann bonds (shock twins) in it has previously been noted by Nininger ${ }^{3}$. The only evidenco for any unusual shock is the presence of small deformation bands (Fig. 2) in the kamacite ( $\alpha$-iron). There were no inclusions in the exposed surface which could be studied crystallographically for shock offects.

Canyon Diablo No. 2. This meteorite falls into the heavily shocked category ( $>750 \mathrm{~kb}$ ) of Heymann et al. ${ }^{7}$. The Widmannstätten pattern is indistinct (Fig. 1) and the kamacito is ontirely recrystallized (Fig. 3). The cohenite $\left(\mathrm{Fe}_{3} \mathrm{C}\right)$ grains show diffusion borders of pearlite. Some ledeburito-like outectic is present and the rhabdites $\left(\mathrm{Fe}_{3} \mathrm{P}\right)$ in the hotter end of the sample are redissolving. The taenite $(\gamma)$ and plessite $(\gamma+\alpha)$ grains are partially or completely clear and there is a secondary kamacite precipitate in some of them. That these thermal effects are due to shock and not to contact with hot ejecta or artificial heating is proved by the crystallo. zones. The taenite and plessite regions are clearing and there is a secondary kamacite precipitate in some taenite bands: the exposed troilite (FeS) nodule of the coarse type 2 variety. A systematic crystallographic study of the cohenite grains in this sample is not yot complete. Those specimens studied thus far fall into the $400-500 \mathrm{~kb}$ range so that there seems little doubt that portions of this meteorite were shocked to pressures of at loast $500 \mathrm{~kb}$.

It is regrettable that the results from the Monument Rock sample permit no absolute conclusion regarding the origin of this meteorite. It could have been part of

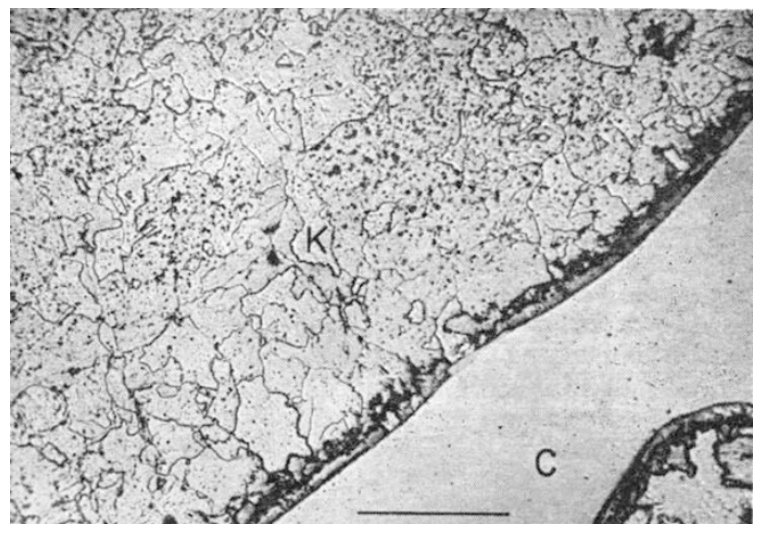

Fig. 3. Microstructure of the heavily shocked Canyon Diablo No. 2 sample showing polycrystalline kamacite $(K)$ and pearlite diffusion border around the cohenite $(C)$

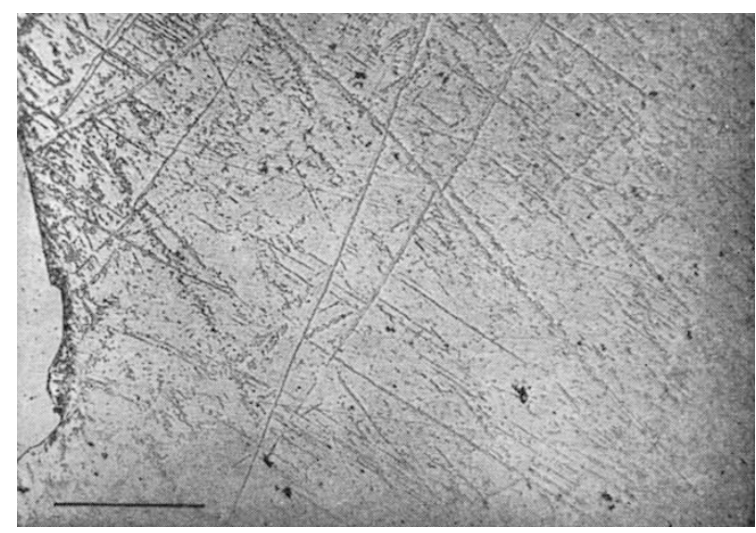

Fig. 4. Microstructure of the moderately shocked Canyon Diablo No. 3 showing $\varepsilon$ iron beginning to recrystallize, particularly on the left at the interface between the cohenite grain and the iron 
the main mass, a satellite of it, or a separate fall. How ever, it should be pointed out that it is indeed a unique sample. Not only is it the only known specimen of its type found at the Crater site but it is also the only known exception to the observation that rim samples (whether of the normal or atypical varieties) have been moderately to strongly shocked.

An unambiguous conclusion can be reached, however, regarding the origin of both Canyon Diablo No. 2 and Canyon Diablo No. 3. These meteorites were involved in a catastrophic explosion during which they were shocked and therefore heated. The narrow widths of the carbon diffusion borders around the cohenite grains indicate that the duration of reheating was short, at most a few minutes, and that the meteorites cooled quickly to below the $\gamma-\alpha$ transformation temperature. Thus, their immediate postshock mass was not considerably larger than their recovered mass. These characteristics are the same as those of the normal shocked Canyon Diablo meteorites. It seems very highly probable, therefore, that both Canyon Diablo No. 2 and Canyon Diablo No. 3 were located in the interior of the meteoroid during the instant of its explosion and were therefore neither satellites of the main mass nor separate later falls. It seems, therefore, reasonable to regard as proved the earlier suggestion ${ }^{6,7}$ that chemical and structural variations do exist in iron meteorites over distances of less than 100 metres.

This work was supported by grants from the Advanced Research Projects Agency and the National Aeronauties and Space Administration.

${ }^{1}$ Bjork, R. L., J. Geophys. Res., 66, 3379 (1961).

${ }^{2}$ Opik, E. J., Irish Astron. J., 5, 14 (1958).

${ }^{3}$ Nininger, H. H., Arizona's Meteorite Crater (American Meteorite Museum, Sedona, Arizona, 1956).

4 Goldberg, E. A., Uchiyama, A., and Brown, H., Geochim. et Cosmochim. Acta, 2,1 (1951)

${ }^{5}$ Barringer, D. M., Meteor Crater in Northern Central Arizona (privately published, 1909).

- Heymann, D., Nature, 204, 819 (1964)

'Heymann, D., Lipschutz, M. E., Nielsen, B. N., and Anders, E., J. Geophys. Res. (in the press).

$\checkmark$ Voshage, H. (personal communication).

- Vilesek, E., and Wänke, H., Proc. Symp. Radioactive Dating, Athens, 1962, 381 (I.A.E.A., Vienna, 1963). Voshage, H., and Hintenberger, H., ibid., 367 .

${ }^{10}$ Lipschutz, M. E., and Anders, E., Geochim. et Cosmochim. Acta, 24, 83 (1961). ${ }^{11}$ Nininger, H. H., Out of the Sky, 234 (Dover, New York, 1952).

${ }^{12}$ Lipschutz, M. E. (in preparation).

\title{
MECHANISM OF STORED-ENERGY RELEASE AT $200^{\circ} \mathrm{C}$ IN ELECTRON- IRRADIATED GRAPHITE
}

\author{
By Prof. E. W. J. MITCHELL and M. R. TAYLOR \\ J. J. Thomson Physical Laboratory, University of Reading
}

$\mathrm{T}$ HE release of stored energy from reactor-irradiated graphite is of considerable physical and technological interest and has been extensively examined. The results are contained in a large number of papers, most points being covered in the following conference Proceedings: the first Geneva Conference on the "Peaceful Uses of Atomic Energy" (1956); the fifth Carbon Conference (1962); the C.E.G.B. Berkeley Conference on "The Properties of Reactor Materials" (1962); and the I.A.E.E. Conference on "Radiation Damage in Reactor Materials" (1963).

For irradiations of low neutron doses the energy is released primarily in the well-known $200^{\circ} \mathrm{C}$ peak in the warm-up curve, although there is a tail to the curve extending to much higher temperatures. Samples irradiated to higher neutron doses, or at higher irradiation temperatures, release relatively less energy in the $200^{\circ} \mathrm{C}$ peak, compared with the higher temperature region ${ }^{1}$. The energy release has been related to neutron dose and temperature systematically by Bell et al. ${ }^{2}$.

The origin of the $200^{\circ} \mathrm{C}$ peak has remained uncertain. Although there had originally been suggestions that it arose from the recombination of interstitial atoms and vacant sites ${ }^{3,4}$, more recently it has been generally considered that the energy was associated with a re-arrangement of displaced atoms in which the vacancy concentra. tion was not significantly altered. The types of model which have been considered may be illustrated by referring to those put forward by Bollman ${ }^{5}$ and Iwata and Suzuki ${ }^{6}$. Bollman has suggested that the process involves the recrystallization of small amorphous regions of up to $60 \AA$ diameter which he assumes are produced by neutron irradiation. According to Bollman, the recrystallized regions may contain some dislocation dipoles, but the region is considered to be of much lower energy than the amorphous region.

On the other hand, it has frequently beon suggested that the stored energy is released when interstitial atoms re-arrange themselves between graphite planes into a lower energy configuration. In the Iwata Suzuki model ${ }^{b}$ it is assumed that relatively loose aggregates of $\mathrm{C}_{2}$ molecules have formed at about room temperature. These aggregates are assumed to produce the $c$-axis unit cell expansion and to be loosely held together through the elastic strain, the electronic binding between the $C_{2}$ molecules being assumed to be small. At $200^{\circ} \mathrm{C}$, Iwata and Suzuki suggest that this loose configuration is converted into the much more stable configuration of the tongue dislocation-not unlike Bollman's dislocation dipole-with a considerable release of energy. Such a process would be accompanied by a recovery in unit cell expansion but the crystal would remain longer than before irradiation.

Each of these models possesses the feature that some disordered arrangement of carbon atoms is converted into a more or less perfect crystal without any interstitialvacancy recombination occurring. Normal graphite has a relatively large interplanar spacing in the $c$-direction and the binding between planes is weak. We expect that the differences between elastic strain energies associated with various interstitial combinations will be small. Energy differences between different structures will then arise primarily from the electronic terms. These can be treated as more or less isolated from the rest of the crystal such that a two-dimensional perfect structure between the planes would have an energy not very different from $a_{0}$ two-dimensional layer in the perfect crystal. We can therefore expect that the energy gain from the re-arrangement of the interstitials will be less than the energy required to dissociate graphite into free carbon atoms in their $t r .{ }^{3} \pi$ graphite valence state. Accordingly, from such models the stored energy $(S)$ will be expocted to be less than the sum of the heat of sublimation $\left(E_{\delta}\right)$ and the promotional energy $\left(E_{p}\right)$ :

$$
S<E_{s}+E_{p}=7.44 \text { (ref. 7) }+6.93 \text { (refs. } 8 \text { and } 9 \text { ) } \mathrm{eV}
$$

per atom involved in the ordering process, or $S<$ about 14-15 $\mathrm{eV}$, there being uncertainty in $E_{p}$.

In order to decide by how much $S$ is less than $14-15 \mathrm{eV}$ on these models we have to specify the electronic state of the distributed interstitials before re-arrangement. If their electronic state were not $t r \cdot{ }^{3} \pi$ but tended more to the free atomic state ${ }^{3} P$, then $S$ would tend to $7 \cdot 44 \mathrm{eV}$ $\left(E_{p} \rightarrow 0\right)$. Similarly, if pairs resembling $\mathrm{C}_{2}$ molecules 